\title{
Factors Affecting The Performance In Statistics Subject Among High School Students In Tripoli, Libya
}

\author{
${ }^{1}$ Serag M. Ali Alwan, ${ }^{2}$ Dr.lr. Ni Wayan Surya Wardhani, ${ }^{3}$ Dr.lr. Maria \\ Bernnadetha Theresia Mitakda \\ Faculty Of Science (Mipa) Brawijaya University Malang-Indonesia
}

\begin{abstract}
This study primarily attempts to investigate if there is any relationship between selected factors namely gender, school factors and academic achievement in Statistics of high school students in Tripoli, Libya. The study specifically answered the following questions

1-Is there any relationship between students' achievement in Statistics and school factors in terms of the Availability and use of school library?

2-Is there any relationship between students achievement in Statistics and the teacher factors in terms of Qualification?

Teacher quality?

Teacher turnover?
\end{abstract}

The sample consisted of 100 science students, 50 males and 50 females from two randomly chosen high schools in Tripoli, Libya.

Two instruments were used in the study. The Statistics achievement test (SAT), was designed to assess student performance in Statistics. The second was a student questionnaire (SQ), designed to obtain information on personal characteristics of the students, school factors.

The main findings of the study are the following:

1. Gender was found to be significantly associated with achievement in Statistics. Specifically, female students were found to perform better than male students.

2. Among the school factors, the factor which emerged as influencing students' achievement in Statistics was the teacher factor. The following are the two elements of teacher factor which were significantly related to students' achievement in Statistics.

(i). Making students understand of what were taught. and

(ii) Teacher's provision of adequate exercises.

Recommendations are offered regarding the need for a multivariate study on a national scale, the need to rethink pre-service and in-service teacher education programmes, origins and consequences of gender differences in performance in Statistics towards improving the level of students achievement in Statistics.

\section{The Background Of The Study:}

\section{Introduction}

Science education has become a major concern in almost all countries and its development has been accorded a high priority. Libya is no exception. Science is taught in Libyan schools at the preparatory level as General Mathematics and as separate subjects - Statistics and Mathematics - at the high school level. The impact of scientific progress, proceeding at a rapid pace, demands that children should receive a sound education in the sciences.

Thus, Statistics concepts common among people for statistics are only numbers and numeric data only, as numbers of the population, and the number of births, deaths, and the numbers of farmers, and the number of farms, etc., and then linked to the concept of people for statistics that count or inventory things and express them with numbers, this is a concept limited to statistics, but statistics as a science is who cares means of data collection, and tabulation, and summarized in can be used to describe and analyze the data to reach sound decisions under conditions of uncertainty. (Derini, without years) (Bozazoh, 1993)

Education in Statistics helps the child to understand the universe and also develops skills such as observing accurately and completely, analyzing, thinking and judging. In addition, it fosters and develops interest, positive values, curiosity and creativity. All these acquired through education in Statistics are required to satisfy the needs of socio-economic development in Libya such as energy, natural resources and productivity. Hence Statistics is of utilitarian value to the child and the society. For the nation to develop economically, it necessitates that the children be literate in Statistics.

Apart from the quantitative expansion in the education system, the Libyan government has made efforts to improve the quality of education at all levels. In the area of science education, including Statistics 
education, at the lower secondary and high school level, the teaching of General mathematics and pure Statistics has been upgraded. Teachers have been trained, facilities have been provided in each school.

However, in spite of the attention given, it is common knowledge that student performance in Statistics examinations is poor. In the 2009 final examinations, Taugihia, only thirty five percent of the students obtained a pass grade in Statistics.

Research findings, to date, on student academic achievement (performance in examinations) have suggested a number of different factors as influencing student performance. This is evident from the mention of the findings of these few studies. For instance,

Bourke (1986) found that teacher effects was stronger than all other school inputs, with the effects becoming more pronounced with increasing grade level. Further, according to the review by Glasman and Biniaminov (1981), some studies have suggested a relationship between performance and the availability and use of the school library.

The findings of past studies, in certain cases, have suggested the same factor as having a different effect in different countries or context. For example, Heyeman and Loxley (1983), contrary to the earlier study mentioned by Coleman et. al. (1966), found that, in lower income countries, that school factors had greater influences. It is clear therefore that attention needs to be paid to research on factors determining student performance in a particular country or context in order to be useful to educators in improving the educational processes towards better student performance.

\subsection{Statement Of Problem :}

The problem is the poor performance and achievement in Statistics by the students studying in high schools in Tripoli, Libya.

\subsection{The Factors Causing The Problem :}

1. Fixed factors, which are beyond the control of educators, specifically the factors of gender and

2. Alterable factors, which may be altered by educators, specifically, availability and use of the school library, qualification of teacher, teacher change frequency, and teacher quality.

More specifically, the researcher sought to answer the following questions:

1. Is there any significant difference between male and female students in their Statistics achievement test?

2. Is there any relationship between students' achievement in Statistics and school factors in terms of the availability and use of school library?

3. Is there any relationship between student achievement in Statistics and the teacher factors in terms of :

i) qualification?

ii) teacher quality?

iii) teacher turnover?

\subsection{Objectives Of The Study :}

This study concerned itself with the levels of performance in Statistics and the factors associated with

it.

The specific objectives of the study were to :

1. determine the level of achievement in Statistics among high school students in Tripoli, Libya, in terms of their performance in a Statistics test, designed by the researcher.

2. determine whether the variable gender is associated with students' achievement in Statistics.

3. determine whether there is an association between students' achievement in Statistics and the availability and use of the school library.

4. determine whether there is any influence of qualified or unqualified teachers, teacher turnover and teacher quality on students' achievement in Statistics.

\subsection{Significance Of The Study :}

The research is of dual significance. Firstly, it adds to our knowledge in the area of determinants of academic achievement. Specifically, the results of the study will provide us with information as to whether the factors such as gender and school factors influence academic achievement in Statistics in the Libyan context.

Secondly, it is hoped that the findings will enable better planning of education in Libya, in terms of the allocation of resources for provision of relevant and necessary school facilities and training of school personnel. The findings of this survey study may indicate some influencing factors, which may be investigated further using an experimental approach to determine the factors linked to academic achievement of students in Statistics. 


\subsection{Limitation Of The Study :}

The investigation is limited to students in Tripoli and to final year high school students. The sample of the study comprised only 100 science students. It does not adopt a causal model which will entail a large sample and a more sophisticated analysis, which is not within the resources of time and money of a single researcher. Further, the study only deals with a few factors, in other words, it is not a multi-variate study.

The instrument used to measure academic achievement in Statistics.

\subsection{Operational Definition Of Terms :}

Academic achievement in Statistics :

The percentage mark obtained by students in the Statistics test designed by the researcher.

School factors :

School factors in this study include school facilities (library) and teacher factors (specifically teacher qualification, teacher turnover and teacher quality) .

High school :

This level follows the three years of preparatory school. Admission to the University is based on the successful completion of this level of education, which is three years.

The certificate earned at the end of the high school is termed Taugihia.

\section{1. Introduction :}

\section{Review Of Related Literature}

The influence of diverse variables such as gender, school facilities and experiences (including teacher quality) on academic achievement of students have been and is continuing to be an area of interest to educators and educational planners both in the developing and developed countries. In other words, many researchers have focused on the important issue of factors influencing student achievement. The question of whether genetic factors, and educational investment of resources into schooling make a difference in educational achievement has been tested by many researchers in many countries at various levels of education. Educational achievement has been taken to mean general school achievement or achievement in specific subject areas.

From among all the factors researched into, in the search for the determinants of academic achievement, it was decided in this study to focus on two groups of factors of interest to the researcher, namely "

i) gender of students.

ii) school inputs, specifically availability and use of a library and certain teacher characteristics

Hence, this review will consider briefly the researches on the relationship or association of the two above-stated group of factors to academic achievement, particular achievement in the sciences.

\subsection{Design Of The Study :}

\section{Research Methodology}

The influence of selected factors on high school students' performance in Statistics was investigated empirically on the basis of a survey of students in terms of their academic achievement in Statistics (dependent variable) and selected influencing factors. The data on the influencing factors (independent variables) were obtained from the students using a questionnaire. The variables examined are listed in the figure below.

Figure 1

Variables in the Study

\begin{tabular}{|l|l|}
\hline Independent Variables & Dependent Variables \\
\hline -Gender & Students' achievement in Statistics test \\
- School factors & \\
- Availability and use of library & \\
- Teacher qualification & \\
- Teacher quality & \\
- Teacher turnover student factors & \\
\hline
\end{tabular}

\subsection{Population And Sampling :}

The population of the study was the high school students in city of Tripoli, Libya. The sample of students was restricted to final year high school students. There were 37 high schools in Tripoli and only 4 high schools were selected for the study. The 4 high schools were selected by cluster random sampling. It was found that in the 4 high schools, the number of year three classes ranged from three to seven. The researcher then selected two classes of students from each school by simple random sampling making a total of 100 students from the two schools. This represented about $2 \%$ of the total students population (100 students of students). 


\subsection{Instrumentation :}

Two instruments were used in the study. The first, the achievement test, was designed to assess student performance in Statistics. The second was a questionnaire, designed to obtain information on personal characteristics of the student and school factors.

3.31. The Statistics Achievement Test (SAT):

The Statistics Achievement Test (SAT) a pencil-and-paper test, was developed by the researcher. The test consisted of 25 multiple choice items, based on the first four chapters of the grade three Statistics text book entitled "General Statistics " for the Libyan High Schools. The test items were drawn up to cover the content and objectives of the area of Statistics already taught by teachers in Tripoli.

\subsection{Validity Of SAT}

SAT consisted of 25 question items. The question items were contructed such that they were representative of the whole domain of content of the four chapters and in accordance with the emphasis given the specific content topics by the teachers. Both the lower (i.e. knowledge and understanding) and higher (application and analysis) levels of cognitive processes were tested by these items.

The draft test comprising 30 items was given to three Statistics lecturers in the department of Statistics of Faculty of Science of the Tripoli University in Tripoli. The lecturers were asked to judge and comment on these 30 items in terms of coverage, phrasing, ambiguities, difficult vocabularies and distractors. This test of 30 items was also pilot tested with a group of 37 high school final year students in one Tripoli school, not included in the sample of the study.

The responses were item analyzed revisions were made based on the comments of the judges and students and the item analysis results. Some items were discarded and the amended test of 25 items was judged by the judges as content valid.

\subsection{Reliability Of The Test :}

For reliability, a random sample of 20 students from one school in Tripoli was chosen for the test-retest procedure, the test being administered two weeks apart. The Spearman correlation $r$ had a calculated value of 0.84 .

3.34. The Student Questionnaire (SQ):

The Student Questionnaire (SQ) , comprising 15 items, obtained information on demographic variables of the students (Items 2-7), school factors (Items 8-15).

The draft questionnaire was given to two lecturers in the Faculty of Education of the Tripoli University in Tripoli. Based on their comments and the data from the pilot testing with 10 students, some items were deleted and revisions were made where necessary. The researcher found no problems with reliability of student responses during the pilot testing.

\subsection{Data Collection Method :}

The researcher obtained official permission to administer the test and the questionnaire to the chosen sample from the High School Office of Education in Tripoli. The test was administered to all the students in each of two grade three classes from each school by the researcher.

At the beginning of the administration of the test and questionnaire, the purpose of the study was explained to the students. The students were not permitted to consult each other during the conduct of the test. The students were given only 30 minutes to complete the test. Upon completion of the SAT, the students were given the questionnaire. The students were given 20 minutes to complete the questionnaire. The administration of the test and the questionnaire to all the sampled students was completed within two days .

\subsection{Analysis Of Data :}

The data collected were coded and analysed. The researcher used the Statistical Packaqe for Social Science (SPSS/PC+) Norusis (1988) for the analysis of the data. Each item of the questionnaire was separately analyzed and cross-tabulated for factors, that is, gender and school variables.

The following analytical procedures were conducted on the coded data:

A t-test was carried out to determine whether there was any significant difference in the performance of male and female students.

Since the data utilized for determining the relationship were of nominal nature, the Chi square test was employed to determine whether students' achievement in Statistics was related to the independent variables, namely availability and use of school library, qualification of teacher, teacher quality and teacher turnover. 


\subsection{Introduction :}

\section{Results And Discussion}

Statistics.

This study focused on the influence of a number of independent variables on students' achievement in

This presents and discusses the results of the analyses of data collected through a student questionnaire (SQ) and an achievement test in Statistics (SAT).

\subsection{Students Achievement In The Statistics Test (SAT):}

Students' achievement in the (SAT) was varied. The highest score obtained in (SAT) was 88 marks and the lowest was 16 marks. Therefore, the range of marks for the sample of students was 72 . The sample of students was categorized into three groups in terms of their performance in (SAT).

Students who obtained scores of 65 marks and above were categorized as high achievers. Students who scored between 41 and 64 marks were categorized as medium achievers. Low achievers were students who scored 40 marks and below. The number and percentage of students in each category was obtained and are as presented in Table I.

Table 1

Student Achievement in SAT

\begin{tabular}{|l|l|l|l|}
\hline Achievement levels & Average Score & Number & percent \% \\
\hline High & $65-88$ & 29 & 29.0 \\
\hline Medium & $41-64$ & 40 & 40.0 \\
\hline Low & $16-40$ & 31 & 31.0 \\
\hline Total & & 100 & 100 \\
\hline
\end{tabular}

The majority, $40.0 \%$ (40) of students appear to fall in the medium level of achievement, though there was a fair proportion $29.0 \%$ (29) of students who obtained high scores, while the remaining $31.0 \%$ (31) of students obtained lower than 40 marks.

4.3. Relationship Between Gender And Academic Achievement :

In order to answer Research Question whether there is any significant difference between male and female students in their Statistics achievement, the mean score and standard deviation for the male and female groups were obtained and a t-test was conducted on the data. The results are presented in Table 2 below.

Table 2

Means and Standard Deviation for SAT by Gender

\begin{tabular}{|l|l|l|l|l|}
\hline \multicolumn{1}{|c|}{ Gender } & Number & Mean Score & St. Devition & t-test value \\
\hline Male & 50 & 54.19 & 13.922 & \\
\hline Female & 50 & 58.86 & 14.311 & $3.58^{* * *}$ \\
\hline
\end{tabular}

Note $* * * \quad \mathrm{P} \leq 0.001$

Table 2 suggests that both sexes on average, had medium achievement level in SAT, but the girls performed significantly better than boys The girls achieved a mean score of 58.86 while the boys had a mean score of 54.19 .

The variable gender was found to significantly influence students' achievement in Statistics $(\mathrm{P}<0.001)$.

A further analysis was conducted to investigate the influence of the gender variable. The sample of male and female students were categorized into three groups in terms of their performance in the SAT as presented in Table.

Table 3 presents the frequencies and percentages of male and female students in the high, medium and low achievement categories.

From Table 3 above, it is observed that only $18.0 \%$ (9) of male students obtained high achievement in the SAT, while a greater proportion, $40.0 \%$ (20) of female students obtained high achievement in the SAT. On the other hand, $38.0 \%$ (19) of males were among the low achievers in the test compared to only $24.0 \%$ (12) of female students who obtained low achievement in the same test (SAT).

It is again clear, from the chi square test performed on data presented in Table 3, that there is a significant relationship between gender and achievement with girls performing significantly better than boys in Statistics, the Statistics Achievement Test (SAT). 
Table 3

Cross-tabulation of Achievement Levels in SAT by Gender

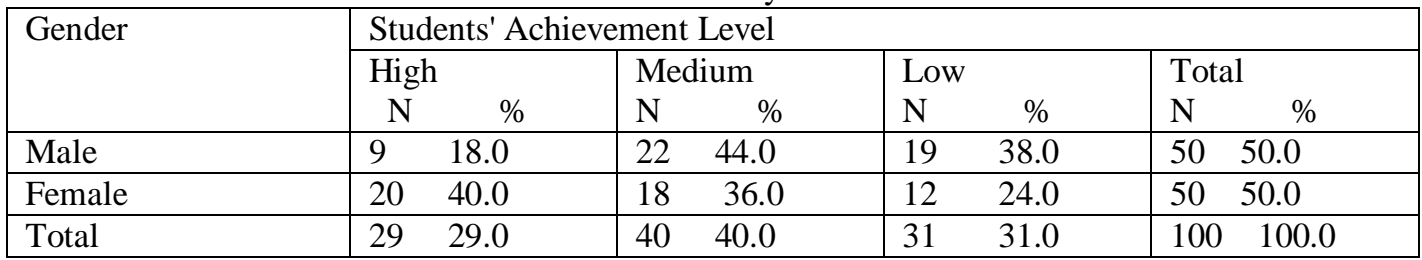

Chi square $=12.64$ at $\mathrm{P} 0.001$,

4.6. The Relationship Between School Factors And Academic Achievement :

The school factors which were investigated in this study included students' perception of availability and use of a library and teacher variables.

4.61. Relationship Between Availability And Use Of Library And The SAT:

The library is described as the hub of a school. This study, hence, investigated the influence of the availability of the library and its use on students' achievement in Statistics.

\subsection{Availability Of Library And The SAT:}

Table 5 presents the relevant data to investigate the relationship between students' achievement in the SAT and students' perception of the availability of school library in order to answer Research Question 6 (ii). The majority, $66.4 \%$ (326) of students indicated that a library is available in their schools, while about $33 \%$ (165) indicated that their schools had no library.

Table 4

Cross-tabulation of Students' Achievement Levels in Statistics by Availability of a Library

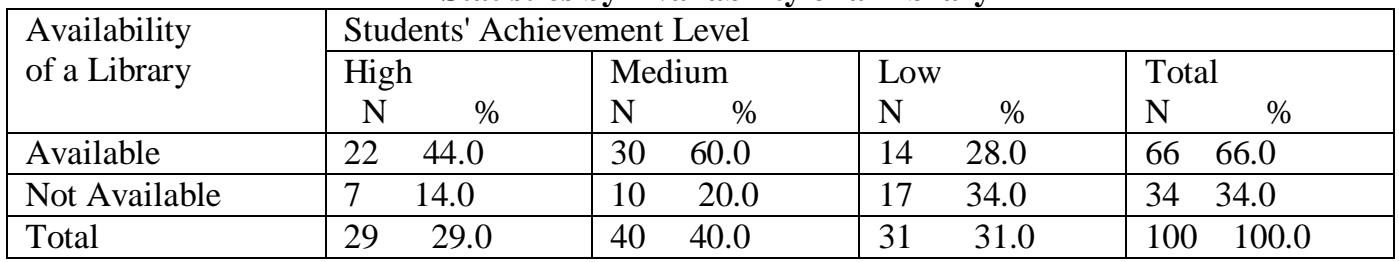

Chi square $=4.0764$, not significant,

From Table 4 above, it is observed that $44.0 \%$ (22) of students, who indicated that their schools had a library, obtained high achievement in the Statistics test, and 14.0\% (7) of students, who indicated that their schools had no library obtained high achievement in the test. On the other hand, $28.0 \%$ (14) of students, who indicated that their schools had a library, obtained low achievement in the Statistics test, compared with $34.0 \%$ (17) of students who indicated that their schools had no library. The data appear to show that students' perception that their schools had a library did not however influence achievement in the SAT.

The Chi square (4.08) obtained from the analysis of data given in Table 4 shows that there is no significant relationship between students' achievement in Statistics and availability of a school library.

\subsection{Use Of School Library And SAT :}

Table 5 presents the relevant data to investigate the relationship between students' achievement in the SAT and students' use of school library. Although more than $66 \%$ professed that their schools had a library (Table 4), only $29.0 \%$ (29) indicated that they made use of the library (Table 5) .

From Table 5 below, it is observed that $24.0 \%$ (12) of students, who indicated that they did not use the school library, obtained high achievement in the Statistics test, while $34.0 \%$ (17) of students, who used the school library, obtained high achievement in the test. On the other hand, $64.0 \%$ (31) of students, who indicated that they did not use the school library obtained low achievement in the test, and $00.0 \%(0)$ of students, who used the school library obtained low achievement in the test. 
Table 5

Cross-tabulation of Students' Achievement

Levels In Statistics by Students' Use of the School Library

\begin{tabular}{|c|c|c|c|c|}
\hline \multirow{3}{*}{$\begin{array}{l}\text { Use of } \\
\text { School } \\
\text { Library }\end{array}$} & \multicolumn{4}{|c|}{ Students' Achievement Level } \\
\hline & High & Medium & Low & Total \\
\hline & $\mathrm{N}$ & $\mathrm{N} \quad \%$ & $\mathrm{~N}$ & $\mathrm{~N}$ \\
\hline Not used at all & 24.0 & $28 \quad 56.0$ & 64.0 & 71.0 \\
\hline Made use of library & 34.0 & 24.0 & 00.0 & 29.0 \\
\hline Total & 29.0 & 40.0 & 31.0 & $100 \quad 100.0$ \\
\hline
\end{tabular}

Chi square $=2.3027$, not significant,

The Chi square analysis of data presented in Table 5 shows that there is no significant relationship between students' achievement in Statistics and the use of the school library (Chi square 2.30, not significant). The findings with regard to use of the school library seem to be consistent with that of availability of school library. It appears that both availability of school library and its use do not influence students' achievement in Statistics.

\subsection{Teacher Variables And The SAT :}

The teacher variables considered in this study include teacher qualification, students' perception of teacher quality and teacher turnover.

\subsection{Teacher Qualification And The SAT :}

In order to answer Research Question, Is there any relationship between students' achievement in Statistics and the teachers ' qualification, the data on teachers ' qualifications were obtained from responses to Item 12 of the student questionnaire (SQ). Table 6 presents the data of investigate the relationship between students' achievement in the SAT and the students' perception of their teachers' qualification.

Table 6

Cross-tabulation of Students' Achievement Levels in Statistics by Students' Perception of Qualification of Teachers

\begin{tabular}{|c|c|c|c|c|c|}
\hline Qualification & Students' A & ment Level & & & \\
\hline & $\begin{array}{l}\text { High } \\
\mathrm{N}\end{array}$ & $\begin{array}{l}\text { Medium } \\
\mathrm{N} \%\end{array}$ & $\begin{array}{l}\text { Lov } \\
\mathrm{N}\end{array}$ & $\%$ & $\begin{array}{l}\text { Total } \\
\mathrm{N}\end{array}$ \\
\hline Qualified & $24 \quad 48.0$ & $25 \quad 50.0$ & 13 & 26.0 & 62.0 \\
\hline Unqualified & $\begin{array}{ll}5 & 10.0\end{array}$ & 38.0 & 18 & 32.0 & 38.0 \\
\hline Total & 29.0 & $40 \quad 40.0$ & 31 & 31.0 & $100 \quad 100.0$ \\
\hline
\end{tabular}

Chi square $=0.31755$, not significant,

From Table 6 above, which presents the data on whether the students perceived their teachers as qualified or not, it is observed that of the $62.0 \%$ (62) of students who indicated that their teachers are qualified, $48.0 \%(24)$ of these students obtained high achievement in the Statistics test, and 26.0\% (13) of these students obtained low achievement.

However, Chi square computed was found to be not significant at the 0.01 level. There appears to be no significant relationship between students' achievement in Statistics and students' perception of their teachers' qualification.

\subsection{Teacher Quality And The SAT :}

In order to answer Research Question. Is there any relationship between students' achievement in Statistics and the teacher quality, the students' perception of the quality of their teachers was obtained from their responses to Items 13 - 15. Students were asked to respond to (i) whether they understand what was taught (Item 13), (ii) whether they needed further explanation in Statistics (Item 14) and (iii) whether they needed more exercises in Statistics (Item 15).

Table 7 presents data on whether or not the students understood what was taught to them in Statistics. Table 7 shows that a large proportion, 57.0\% (57) of students indicated that they understood Statistics taught by teacher while $43.0 \%$ (43) of students stated that they did not understand Statistics taught to them.

From Table 7 below, it is observed that a higher proportion, 58.0\% (29) of students, who indicated that they understood Statistics taught by the teacher, obtained high achievement in the Statistics test as compared to $6.0 \%$ (3) of students who obtained a low level of achievement. 
On the other hand, at $43.0 \%$ (43) of those who stated that they did not understand Statistics as taught by the teacher, only $0.0 \%$ (0) obtained high achievement, while $56.0 \%$ (28) obtained a low level of achievement in the SAT.

Table 7

Cross-tabulation of Students' Achievement Levels in Statistics by Whether Students' Understood Statistics from Teacher

\begin{tabular}{|c|c|c|c|c|c|c|}
\hline \multirow{2}{*}{$\begin{array}{l}\text { Understood } \\
\text { Statistics from } \\
\text { Teacher }\end{array}$} & \multicolumn{6}{|c|}{ Students' Achievement Level } \\
\hline & $\begin{array}{l}\text { High } \\
\mathrm{N}\end{array}$ & $\begin{array}{l}\text { Medium } \\
\mathrm{N} \%\end{array}$ & $\begin{array}{l}\text { Lo } \\
\mathrm{N}\end{array}$ & $\%$ & $\begin{array}{l}\text { Total } \\
\mathrm{N}\end{array}$ & $\%$ \\
\hline Yes & $29 \quad 58.0$ & 50.0 & 3 & 6.0 & 57 & 57.0 \\
\hline No & $\begin{array}{ll}0 & 00.0\end{array}$ & 30.0 & 28 & 56.0 & 43 & 43.0 \\
\hline Total & $29 \quad 29.0$ & 40.0 & 31 & 31.0 & 100 & 100.0 \\
\hline
\end{tabular}

Chi square $=35.27$ at $\mathrm{P} 0.001$,

The Chi square was found to be 35.27 and was significant at the 0.001 level. It is therefore clear that there is a significant relationship between perceived teacher quality with respect to teacher's ability to make students understand and students' achievement in Statistics.

Table 8 presents the frequencies and percentages of students' in the high, medium and low achievement categories by students need for further explanation. From Table 8 below, it is observed that a larger proportion, $54.0 \%$ (27) of the students who indicated that they needed extra explanation in Statistics obtained low achievement in the Statistics test, but only $20.0 \%$ (10) of the students obtained high achievement in the Statistics test.

On the other hand, while $38.0 \%$ (19) of the students who indicated that they did not need extra explanation in Statistics obtained high achievement in the Statistics test, 8.0\% (4) of the students obtained low achievement.

\section{Table 8}

Cross-tabulation of Students' Achievement Levels in Statistics by Students' Need for Extra Explanation

\begin{tabular}{|c|c|c|c|c|c|c|}
\hline Need for & \multicolumn{6}{|c|}{ Students' Achievement Level } \\
\hline $\begin{array}{l}\text { Extra } \\
\text { Explanation }\end{array}$ & $\begin{array}{l}\text { High } \\
\mathrm{N} \%\end{array}$ & $\begin{array}{l}\text { Medium } \\
\mathrm{N} \%\end{array}$ & $\begin{array}{l}\text { Lo } \\
\mathrm{N}\end{array}$ & $\%$ & $\begin{array}{l}\text { Total } \\
\mathrm{N}\end{array}$ & $\%$ \\
\hline Yes & 20.0 & $20 \quad 40.0$ & 27 & 54.0 & 57 & 57.0 \\
\hline No & 38.0 & 40.0 & 4 & 8.0 & & 43.0 \\
\hline Total & 29.0 & $40 \quad 40.0$ & 31 & 31.0 & 100 & 100.0 \\
\hline
\end{tabular}

Chi square $=12.37554$ at $\mathrm{P} 0.001$

The Chi square computed (12.38) was found to be significant at the 0.01 level therefore, be inferred that of significance. It may, there is a significant relationship between achievement in Statistics and teacher quality in terms of the students' need for extra explanation.

Table 9 presents the frequencies and percentages of students in the high, medium and low achievement categories by students' demand for extra exercises in Statistics. Table 9 shows that a high proportion of students $61.0 \%$ (61) indicated that they needed extra exercises in Statistics, in other words that the teachers did not give them enough exercises in Statistics. From the same Table 9 below, it is observed that a smaller proportion $30.0 \%$ (15) of students who expressed that they needed extra exercises in Statistics obtained high achievement in the Statistics test, compared with $46.0 \%$ (23) of students who obtained low achievement in Statistics.

Further, a larger proportion, $30.0 \%$ (15) of students who expressed that they did not need extra exercises in Statistics obtained a high achievement, while only $16.0 \%$ (8) who indicated that they did not need extra exercises obtained low achievement. 
Table 9

\section{Cross-tabulation of Students' Achievement Levels in Statistics by Students, Demand for Extra Exercises in Statistics}

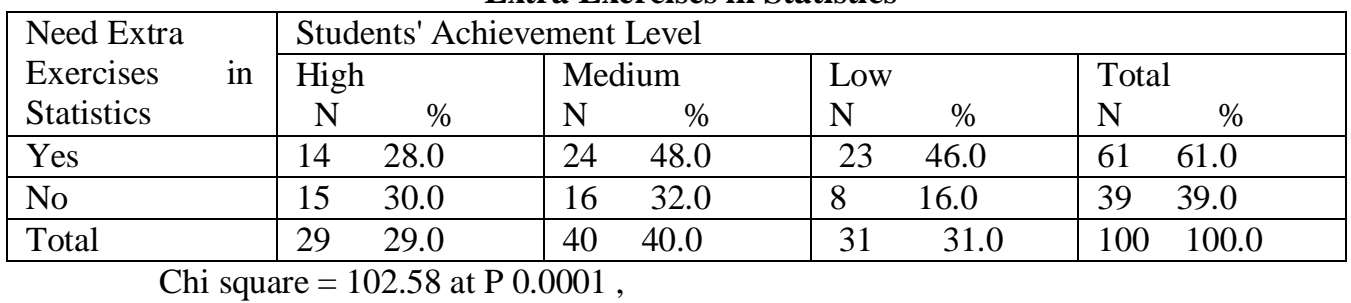

The Chi square computed (102.58) was found to be significant at the 0.0001 level of significance. It may, therefore, be inferred that there is a significant relationship between student achievement in Statistics and extent of exercises given by teacher. To conclude, teacher quality in terms of teacher explanation and teacher provision of enough exercises appears to be significantly related to students' achievement in Statistics.

\section{633. Teacher Turnover And The SAT :}

The effectiveness of Statistics teaching may be affected by teacher turnover and hence one of the questions of this study was whether there is any relationship between students' achievement in Statistics and teacher turnover. In order to answer this question one of the statements in Item 12 required students to indicate whether Statistics teachers are changed during the period of the year.

Table 10 presents the relevant data to investigate the relationship between students' achievement in the SAT and students' perception of teacher turnover.

Table 10

Cross-tabulation of Students' Achievement Levels

in Statistics by Teacher Turnover

\begin{tabular}{|c|c|c|c|c|c|c|}
\hline Statistics & \multicolumn{6}{|c|}{ Students' Achievement Level } \\
\hline Teacher & High & Medium & & & Tota & \\
\hline Turnover & $\mathrm{N}$ & $\mathrm{N} \quad \%$ & $\mathrm{~N}$ & $\%$ & & $\%$ \\
\hline Yes & 18.0 & 14.0 & 9 & 18.0 & 25 & 25.0 \\
\hline No & 40.0 & $\begin{array}{ll}33 & 66.0\end{array}$ & 22 & 44.0 & 75 & 75.0 \\
\hline Total & 29.0 & 40.0 & & 31.0 & 100 & 100.0 \\
\hline
\end{tabular}

Chi square $=4.91612$ at $\mathrm{P}<0.01$

About a quarter of the students sampled indicated that their Statistics teachers were changed during the year. Hence, there is a fair amount of teacher turnover. From Table 10 above, it is observed that only $18.0 \%$ (9) of students whose Statistics teachers were changed throughout the year obtained high achievement in the test, while $18.0 \%$ (9) of students obtained low achievement in the test.

However, the Chi square analysis on the data given in Table 10, produced a non-significant result. Teacher turnover therefore, does not appear to influence students' achievement in Statistics.

4.64. Summary Of The Relationship Between The School Factors And Student Academic Achievement :

The tables above summarizes the aspect of the relationship of school variables and students' achievement in Statistics. As shown by the values of Chi square, it is clear that the teacher variable appears to be the more important factor influencing Statistics learning than availability of school library. The perceived quality of the teacher in terms of making students understand Statistics and providing students with extra exercises appear to be the important teacher variables influencing students' achievement in Statistics. This seems reasonable since the teacher is the person who provides the learning experience for the students.

\subsection{Conclusion :}

\section{Conclusions And Recommendations}

This study set out to examine certain variables which might have some bearing on the level of performance of students in the high schools in Tripoli, Libya in the field of Statistics. The performance of students measured was restricted to cognitive development in Statistics. The population of the study was final year high school students. There were 37 high schools in Tripoli and only 4 high schools were selected for the study. The 4 high schools were selected by cluster random sampling. A total of 100 students took part in the study. The sample used represented about $2 \%$ of the total student population (7639 students). Two instruments were used in the study. The first, the achievement test, (SAT), was designed to assess student performance in 
Statistics. The second was a student questionnaire, (SQ), designed to obtain information on personal characteristics of the student, school factors and student factors.

The performance of students was found to be varied (the range being 72 marks). The determinants of this variability in achievement in Statistics were the interest of this research.

In this section, the major conclusions derived from the study will be summarized. In addition, the findings will be related to past research studies, and their implications will be discussed.

Gender was found to be significantly associated with achievement in Statistics. Specifically, female students were found to perform better than male students.

Whether this is the case in Libya needs to be substantiated by further research.

Among the school factors, the factor which emerged as influencing students' achievement in Statistics was the teacher factor. Specifically two elements of teacher factor, that is, clarity of presentation, in other words, making students understand what they are taught and teacher provision of adequate exercises were found to be significantly related to students' achievement in Statistics.

The library was also not found to be influencing students' achievement in Statistics, here was no significant relationship of availability of library and students' achievement in Statistics was found.

Among the two student factors investigated namely, students interest in Statistics and students perception of the value of Statistics in society, the factor which emerged as influencing students' achievement in Statistics was students ' interest in Statistics. The study found a significant relationship between students' achievement in Statistics and their interest in Statistics.

Further, a significant though weak, relationship between students' achievement in Statistics and students' perception of value of Statistics in society was found.

\subsection{Recommendation :}

The results of these analyses might perhaps be taken as indicators for the need for a more detailed study to be carried out on the problem of students' level of achievement in Statistics in Libya. The present work, devoted to certain High Schools in Tripoli, could only be considered as an exploratory study. It is to lay the ground work touching on certain pressing issues while leaving the more deep-seated questions to be tackled in a more elaborate study.

The study, specifically, only concerned itself with the relationship between selected variables and student growth in the cognitive domain. Hence, student growth in areas other than the cognitive area needs to be studied. Since school learning, specifically Statistics learning, is a complex phenomenon with many variables involved and the variables interacting with one another, a multi-variate study on a national scale is recommended. This multi-variate study will be invaluable to shed light on the ways the social, political and educational factors operate and influence student learning.

The main concern, as it is with every educationist, had been the child's performance. The child's learning being the central focus, the educational process needs more attention, hence the influence of teacherstudent interactions in the classroom on Statistics achievement needs to be undertaken through use of survey and observational strategies. Further, the teacher factors, specifically teacher quality in terms of clarity of presentation and provision of adequate work exercises for students to practice and consolidate the application of knowledge and skills, emerged as an important variable influencing students' achievement. This points to a need to rethink the preserves and in-service teacher education curricula and teacher preparation methods. Variables demonstrated as important such as teacher clarity of presentation need to be broken down into specific behaviors which are presumed to comprise them and these specific behaviors need to be developed in the teachers so as to improve the quality of teachers.

Further, it is recommended that special courses, seminars and workshops for the teachers be provided, on a regular basis, to encourage them to develop their knowledge and skills and hence improve student achievement in Statistics.

The teachers also need to be skilled in the effective use of the school library to promote students learning. Further, the teachers should be able to develop interests in Statistics among their students through being able to engage students effectively in class activities and in science society activities.

Gender was found to influence students' achievement within the sample studied. Nature of gender differences at all levels of education need to be examined in addition to the origins of gender related differences in the children and consequences of gender differences.

To conclude, this study on the factors contributing to differences in achievement in Statistics has merely scratched the surface but has identified some variables which are associated with achievement in Statistics. However, further research (survey and experimental studies) is still needed to guide the practice of Statistics education towards improving the level of students' achievement in Statistics. 


\section{Bibliography:}

[1] Anderson, L.W. (1987) . "The Classroom Environment Study- Teaching for Learning". Comparative Education Review, 31(i) • 6987

[2] Benbow, C.P. and Arjmand, O. (1990) Predictors of High Academic Achievement in Mathematics and Science by Mathematically Talented Students- A Longitudinal Study. Journal of Educational Psychology. 82 (3) • 430-441.

[3] Bourke, S. (1986) "How Smaller is Better- Some Relationships Between Class Size, Teaching Practices, and Student Achievement", American Educational Research Journal, .v. 23, no. (4) ,1986, 558-71.

[4] Boyle, G.J. and Start, K.B. (1989). "Sex differences in the prediction of academic achievement using the children's Motivation Analysis Test". British Journal of Educational Psychology, 59 • 245-252.

[5] Coleman, J.S., et al (1966) Equality of Educational Opportunity. Washington, D.C. • U.S. Government Printing Office.

[6] Drew, D. and Gray, J. (1990) . "The fifth year examination achievement of black young people in England and Wales". Educational Research, $32(2) \cdot 107-117$.

[7] Eccleston, G., Borkin, I. and Burraos, A. (1990). "Sex-related differences in an academic performance at G.C.E. (A) level. Educational Research, 32 (3) • 229-232.

[8] Erickson, G.L. and Erickson, L.J. (1984). "Females and science achievement- achievement, evidence, explanations and implications". Science Education, 68(2) • 63-89.

[9] Fennema E. and Sherman J. (1977). Sex-related differences in Mathematics achievement, spatial visualisation, and socio cultural factors, American Education Research Journal, 14(1) • 51-71.

[10] Gallagher, J.J. (1987). A summary of research in science education. Science Education , 71" 277-284.

[11] Glasman, N.S. and Biniaminov, I. (1981) "Input-output analysis of schools, Review o f Educational Research, 51(4) • 509-39.

[12] Heyneman, S. P. (1976). Influences on Academic Achievement : A comparison of results from Uganda and more Industrialized Countries. Sociology off Education, $49 \cdot 200-211$.

[13] Heyneman, S.P. and Loxley, W.A. (1982). "Influences on academic achievement across higher and lower income countries " A reanalysis of IEA data". Sociology off Education, 55(1)- 13-21.

[14] Husen, Torsten.et al. (1978) . Teacher Training and Student Achievement in less Developed Countries . Washington,D.C. World Bank . 1978

[15] Lijnse, P. (1983) "Does science education improve the image of science?". Science Education, 67- 577-82.

[16] Mahmoed Derini, without years, Definition of Statistics. Website: (http://www.bsofian-ksu.com/agec613/Lecture1.pdf

[17] Mustafa Bozazoh, 1993, the statistical methods used in educational assessment, book Rawasi (1), (Readings in Educational Evaluation), written by a group of professors, the Social Reform Society, educational, Batna, Algeria.

[18] Norusis. M. J. (2008). Statistical Package for Social Science (spss / PC +)

[19] Theisen, G. L., Achola, P. P. W. and Boakari, F. M., (1983). The underachievement of cross-national studies of achievement. Comparative Education Review, 27(i) • 46-68. 